\title{
Investigation of Effective Parameters of Drop-on-Demand Droplet Generator
}

\author{
M.S. Sarebandia, M. Ghodsi ${ }^{*}, \mathrm{~b}$, Y. Hojjata, H. Sadeghiana, H. Ziaiefarb, M. Mohammadzaheri ${ }^{\mathrm{b}}$ \\ and A. Al-Yahmedib \\ a Department of Mechanical Engineering, Tarbiat Modares University, Tehran, Iran. \\ ${ }^{b}$ Mechanical and Industrial Engineering, College of Engineering, Sultan Qaboos University, Muscat, Sultanate of Oman.
}

Received 12 March 2017; Accepted 8 October 2017

\begin{abstract}
This article presents a design and development of a drop-on-demand (DOD) droplets generator. This generator uses molten metal as a liquid and can be used in fabrication, prototyping and any kind of printing with solder droplets. This setup consists of a vibrator solenoid with tunable frequency to produce a semi-spherical shape of molten metal, close to the surface of fabrication. This design also has a nozzle with micro-size orifice, a rod for transmitting force and a heater to melt the metal and keep it in superheat temperature. This DOD can produce droplets in different sizes (less than $550 \mu \mathrm{m})$ by controlling the vibration frequency of solenoid. This ability together with the accuracy of the droplets in positioning (the error is less than $\pm 20 \mu \mathrm{m}$ for $1.5 \mathrm{~mm}$ amplitude) can be used in different applications. Moreover, in this paper, the impact of initial position of the head and temperature on the average diameter of droplets and the impact of the frequency on the shape of the droplets have been tested and discussed
\end{abstract}

Keywords: Drop-on-demand; Metal droplets; Rapid prototyping fabrication; Solenoid transduce.

$$
\begin{aligned}
& \text { إختبار معاملات التغير الفعالة لمولد القطرة المسعى قطرة عند الطلب }
\end{aligned}
$$

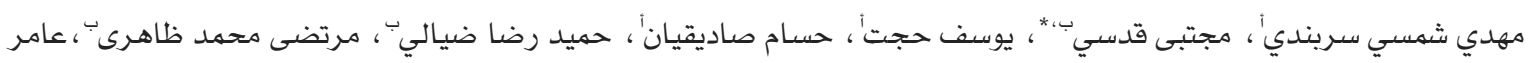

$$
\begin{aligned}
& \text { اليحمديب } \\
& \text { الملخص: تقدم هذه المقالة تصهيها وتطويرا لمولد القطرة المسهى قطرة عند الطلب (DOD). يقوم هذا المولد باستخدام المعدن } \\
& \text { المنصهر كسائل ويمكن استخدامه ِِّ التصنيع والقولبة وأي نوع من أنواع الطباعة بقطيرات سبائك اللحام. ويتكون هذا } \\
& \text { الجهاز من ملف لولبي هزاز ذو تردد موقوت لإنتاج شكل شبه دائري من المعدن المنصهر يشبه كثيرا السطح المصنح. و يوجد } \\
& \text { بهذا التصميه أيضا فوهة ذات فتحة صغيرة الحجم وقضيب لنقل الطاقة وسخان لإذابة المعدن والحفاظ عليه فِّ درجة حرارة }
\end{aligned}
$$

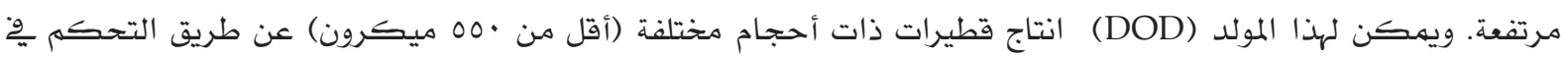

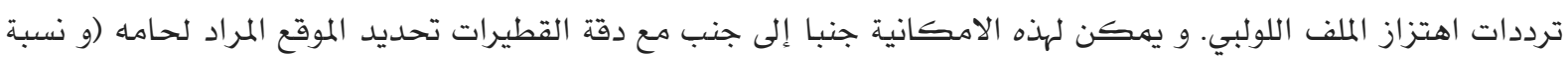

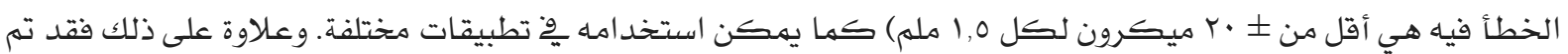

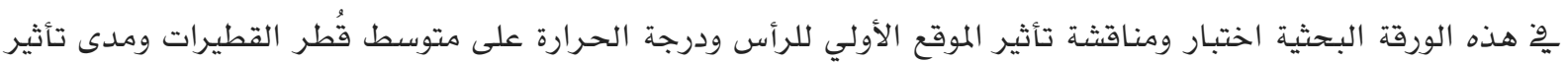

$$
\begin{aligned}
& \text { التردد على شكل القطيرات. } \\
& \text { الكلمات المفتاحية : قطرة بناء على الطلب قطرات معدنية؛ تصنيع النماذج الأولية السريعة؛ محول الملف اللولبي }
\end{aligned}
$$

*Corresponding author's e-mail: ghodsi@squ.edu.om 


\section{Introduction}

Metal DOD generators have become a useful tool in prototyping devices, layer-by-layer fabrication, solid fabrication, solder droplet printing and surface treatment. Recently, due to their cheap price, droplets have attracted more attention. Droplets can be tuned for different applications, from their old version which has been used for printing (Waldvogel et al. 1996) to newer metal DODs that can be used as 3D printers for prototyping (Lawrence et al. 2017). At present, DODs have complex technology and therefore they are not very common. Producing a DOD needs several manufacturing processes (etching, sputtering and so on) that are time consuming (Liu and Orme 1999). Recently, researchers conducted many studies to overcome the aforementioned drawbacks and develop a cheaper and simpler DOD. These generators mainly include a droplet producer unit and a droplet deposition unit. In the former unit, a heating furnace melts metal to a specific temperature; and a vibrator ejects droplets from a nozzle using pulses passing through the molten metal (Sohn and Yang 2005). The nozzle orifice and the latter unit deposit the droplets. In addition to DODs, continuous droplet generators are another type of Metal droplets generators. Although these two methods of drop generating have some differences, both use periodic pulses to eject the molten metal drops through the nuzzle (Sohn and Yang 2005). For soldering droplets printing, continuous rows of droplets are ejected to produce a line or stream on the board. This uniform metal droplets can be produced by exciting a laminar molten metal jet. Formation by using continuous drops of liquid from a steam was examined by Savarat (1833), and many years later, Rayleigh developed its mathematical equation (Rayleigh 1878; Rayleigh 1879). Working frequency of DOD depends on many factors like the speed and the size of drops. The frequency has a wide range between 5 to $44 \mathrm{kHz}$, and lower frequency means larger drops (Liu and Orme 1999). On the other hand, for printing using drop-ondemand, the system can generate a discrete row of metal droplets to make the desired form. As an example, Yamaguchi uses a chamber attached to a diaphragm to eject metal for fabrication. Yamaguchi has used piezoelectric as a vibrator (Yamaguchi et al. 2000). Moreover, Jun Luo showed that it is possible to make a drop-on-demand droplet generator by controlling the pneumatic force of gas as a pressure source (Jun Luo et al. 2012). Piezoelectric buzzers can be implemented in DODs for a room temperature liquid (KuangChao Fan 2008). Using a piezoelectric vibrator (Sadeghian et al. 2013; Mohammadzaheri et al. 2017) or Magnetostrictive one (Ghodsi et al. 2017; Karafi et al. 2015; Ghodsi et al. 2010; Ghodsi et al. 2008), DOD can reach high frequency of vibration; on the other hand, the harsh environment (high temperature) can limit their use in DODs.

The main aim of this research is to design and fabricate a DOD generator with the ability of controlling the size and position of drops in 2-D surface. Moreover, in this article, the impact of different factors such as temperature of superheating metal, position of transmitting rod at the beginning, frequency of generator and amplitude of impulse-transmitting rod will be discussed. Figure 1 shows the schematic view of the DOD.

\section{Experimental Setup}

As shown in Fig. 1, the experimental setup consists of a vibrator as an impulse generator, a rod to transmit the impulses, a micro-nozzle, a tubular shape container for molten metal and a heating part for heating the metal to a desired temperature. The source of vibration is a precise solenoid at the top of the generator.

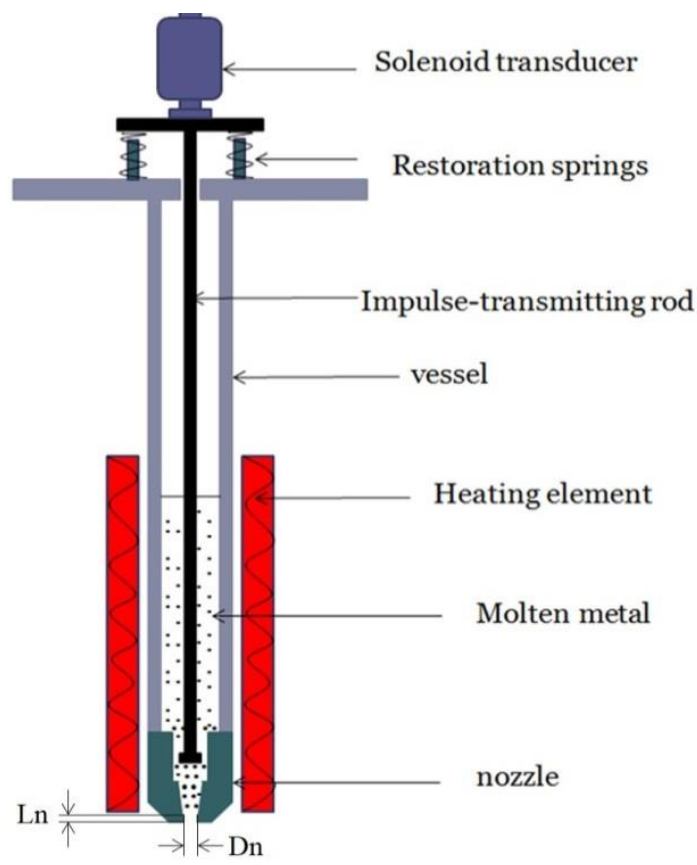

Figure 1. Schematic of the fabricated generator. 
After that, an impulse-transmitting rod transmits the impulses to the metal chamber. The rod is placed near the orifice of the nozzle at the beginning. The vibrator generates the impulses and accordingly, the molten superheated metal is ejected from the nozzle. Four springs are attached to bring the rod back to the initial place for another ejection. Sticking of the molten metal to the surface of the droplet generator is very common. The main reason is the small size of the orifice. To prevent the nozzle getting stuck with materials, non-wetting liquids should be used for injection process, like ceramic materials. However, by choosing a proper material for nozzle, this problem can be reduced. For instance, in previous research, stainless steel was reported as a nozzle material for tin (Sohn and Yang 2005). Hence, some stainless steel parts are in contact with tin (SUS303). Several factors influence the size of drops, one of them is the size of the nozzle orifice. To produce spherical drops, the shape of nozzle orifice has to be perfectly round. Moreover, the aspect ratio of the nozzle is important for ejection of droplets. Ln/Dn must be equal to or smaller than one to break the drops more easily (Sohn and Yang 2005). The diameter of orifice is $198 \mu \mathrm{m}$, and the length is $180 \mu \mathrm{m}$. Hence, the aspect ratio of micro-drilled orifice is 0.90 and less than one. For melting the metal and keeping it in superheat temperature, a tubular heating element was used. This heater can produce temperatures up to $700^{\circ} \mathrm{C}$. For sensing the temperature, a $\mathrm{K}$ type thermocouple is placed into the cylinder hole (drilled hole) to be close enough to the nozzle. To control the temperature of the heater at the specific desired temperature, proportional-integral-derivative method was employed. In this study, droplets of $\mathrm{Sn63/pb37}$ are produced by the presented setup. Table 1 summarizes the physical properties of Sn63/pb37.

\section{Solenoid Design}

In order to evaluate the required force of transducer to eject the molten metal out of the

Table 1. Physical properties of Sn63/pb37.

\begin{tabular}{|c|c|c|c|}
\hline $\begin{array}{l}\text { Viscosity } \\
\left(10^{-3} \text { Pa.s) }\right.\end{array}$ & $\begin{array}{l}\text { Density } \\
\left(\mathrm{kg} \cdot \mathrm{m}^{-3}\right)\end{array}$ & $\begin{array}{l}\text { Surface } \\
\text { tension } \\
\left(\mathrm{N} \cdot \mathrm{m}^{-1}\right)\end{array}$ & $\begin{array}{l}\text { Melting } \\
\text { tempera- } \\
\text { ture }\left({ }^{\circ} \mathrm{C}\right)\end{array}$ \\
\hline 1.33 & 8420 & 0.49 & 183 \\
\hline
\end{tabular}

orifice, Bernoulli's equation in fluid dynamics was used. The flow rate is $\mathrm{Q}=\mathrm{UA}$, where $\mathrm{U}$ is the flow speed of the molten metal and A is the cross-sectional area. From the continuity equation and according to the law of conservation of mass, flow speed of the liquid and droplet, a force of magnitude $0.09 \mathrm{~N}$ is required to be exerted on the plunger to make molten metal squirt from the orifice.

In this setup, a solenoid is used as a force generator. In a solenoid, number of turns, air gap, size of solenoid, the characteristic of the steel of solenoid are factors that have impact on the produced force. To have the desired force for transducer, a coil with 200 turns of wire with $0.45 \mathrm{~mm}$ diameter was used. Using this solenoid, the amplitude of displacement is 3 $\mathrm{mm}$, and maximum payload is $9.05 \mathrm{~N}$. Force equations and solenoid equations can be found in Appendix A. During the experiment, the payload can be adjusted by controlling the current. For adjusting the initial position of the plunger, a number of washers were used.

\section{Effective Parameters on Size of Droplet's}

To have an acceptable DOD for droplet manufacturing, several experiments had been conducted to study the impact of different parameters on the characteristic of metal droplets.

\subsection{Temperature of Molten Metal and Position of Head at the Beginning $\left(L_{h}\right)$}

The melting temperature of $\mathrm{Sn} 63 / \mathrm{pb} 37$ is $183^{\circ} \mathrm{C}$. At this temperature, the viscosity of metal is not low enough to be used in the DOD (Manko 1979). To reach the desired viscosity, the temperature was set at 260,290 , and $320^{\circ} \mathrm{C}$. In this temperature, the molten metal is in a superheated condition. Another factor for optimization is the gap between the head end of transmitting rod and the chamber. This factor has an impact on the efficiency of material supply for dropping and impulse transfer. In this design, this clearance is set at $125 \mu \mathrm{m}$, the vibration frequency $\left(f_{\text {sol }}\right)$ is set at $3 \mathrm{~Hz}$, displacement $(A)$ is set at $0.5 \mathrm{~mm}$ and $40 \mathrm{ml}$ of the melted metal is inserted in the tubular vessel. Figure 2 shows the relationship between the position of the head end at the beginning and temperature of the molten metal and their effect on the diameter of spherical droplets. To have better estimation, the average diameter of 10 droplets was calculated. As it is shown in Fig 2 , by increasing the temperature of the super- 
heated metal, the diameter of droplets decreased. This happens because higher temperature decreases the viscosity and surface tension of the metal (Beer 1972), therefore, the superheated metal can flow through the orifice more easily.

In the test where $L_{h}$ (initial position) was smaller than $1.5 \mathrm{~mm}$, an ejected droplet lost its unity and became two or more separated droplets. The reason is due to the excessive force of the solenoid. In positions higher than $4.5 \mathrm{~mm}$, droplets fell down continuously because of gravity.

\subsection{Amplitude of Displacement and the Position of Head at the Beginning}

The effect of the position of the head at the beginning and amplitude on the size of drop lets are shown in Fig 3.

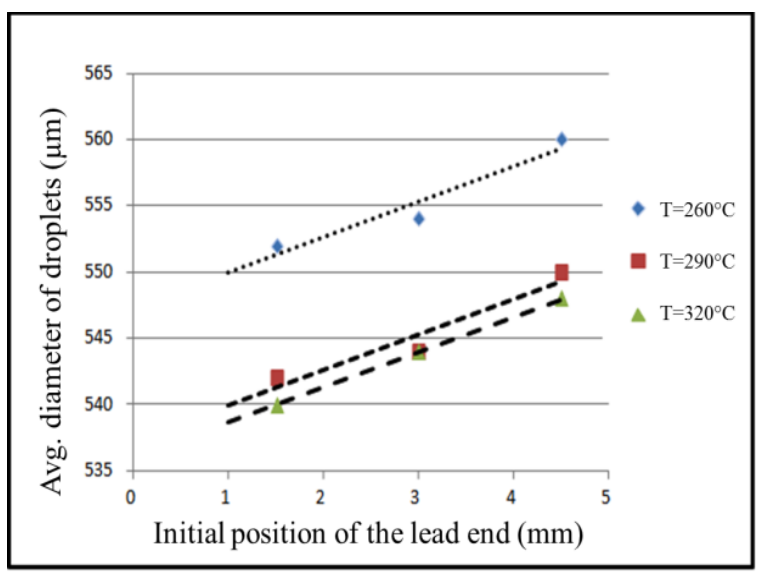

Figure 2. Impact of temperature and the position of the head at the beginning on the size of droplets.

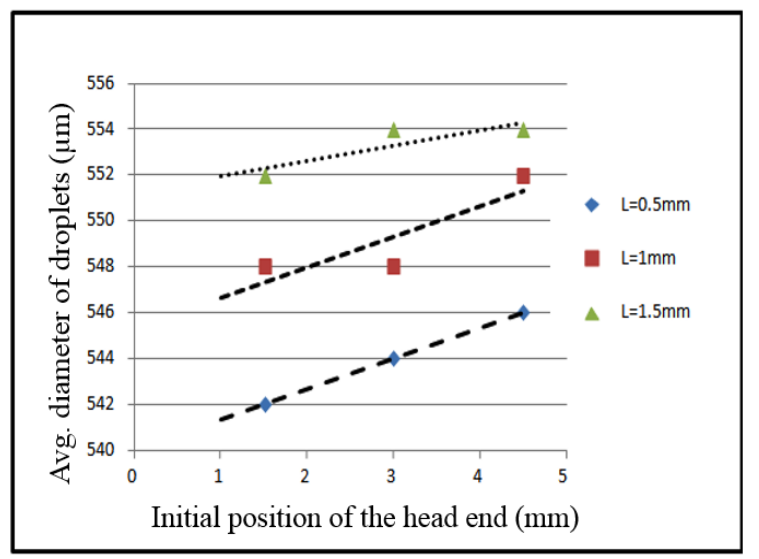

Figure 3. Effect of the position of the head at the beginning and amplitude on the size of droplets.
To investigate the effect of amplitude on the size of droplets, using amplitude limitation washers, which are located on the top of the actuator, displacement amplitude of solenoid (A), were set at $0.5,1$ and $1.5 \mathrm{~mm}$. In this experiment, the temperature is set at $290^{\circ} \mathrm{C}$ and other parameters such as the gaps between the slot of the nozzle and the head of impulsetransmitting rod, the frequency of the solenoid and melted metal inserted in the tubular vessel are set as in the previous experiment.

Figure 3 shows that by increasing the gap size of the head end position, the size of droplets increases. With increasing amplitude of the transducer, the average of droplet diameter increases too. When the amplitude increases, the impulse-transmitting force in the nozzle chamber increases too, thus, more melted metal is ejected from the nozzle orifice, and larger droplets are produced. The corresponding range of droplet diameter is between $542 \mu \mathrm{m}$ and $554 \mu \mathrm{m}$.

\subsection{Solenoid Vibrator Frequency}

To study the effect of frequency, droplets are produced and analyzed at different frequencies, and in each case, more than 10 measurements on droplets size are carried out. In these experiments, displacement amplitude is set at $0.5 \mathrm{~mm}$, and other parameters are set as in the previous experiment. Figure 4 shows photographs of the products of molten metal ejected from nozzle orifice at different frequencies.

Figure 4. ((a)-(c)) visualized the top view of deposited droplets and their diameter. In Fig. 4 ((a)-(c)), the droplets have a number of edges caused by the solidification of the solder at very low frequencies (Goldin 1999). As it can be seen in Fig. 4, at lower frequencies, the shape of the droplets is better and closer to spherical shape. The main reason is that when the frequency is low the molten metal has enough time to eject from the nozzle and has time to become solid. At low frequencies, time is enough for a droplet not to have a negative impact on the previous or next drops. On the other hand, at higher frequencies, because of surface tension between the droplets and viscosity, there is no enough time for the material to break and make spherical separated droplets. At last, the molten metal will become solid in the intended line of fiber. Figure $4((\mathrm{~d})-(\mathrm{f}))$ shows the solid droplets of metal after dropping. 


\section{Positioning of Drop-on-Demand Droplets}

The accuracy of prototyping and fabrication by a DOD generator depends on the droplets precise location and the frequency of the drop. To test the drop-on-demand capability, the temperature of the device was set at $\mathrm{T}=290^{\circ} \mathrm{C}$, and the frequency of dropping was set at $3 \mathrm{~Hz}$, and the gap between the head of the nozzle and surface was maintained at $5 \mathrm{~mm}$. Experimentally, the velocity of the droplets Was calculated around $\mathrm{v}=10 \mathrm{~mm} / \mathrm{s}$. The setup of the experiment and the results of the tests are shown in Fig 5. Figure 5. shows a row of droplets in a specific location (according to frequency). The result of the tests shows that the setup works correctly, and the droplets are in the intended positions. To calculate the droplets velocity, a high-speed camera captured a series of photos.

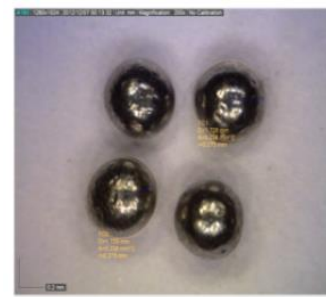

(a) $f=0.33 \mathrm{~Hz}, \mathrm{D}=558 \mu \mathrm{m}$

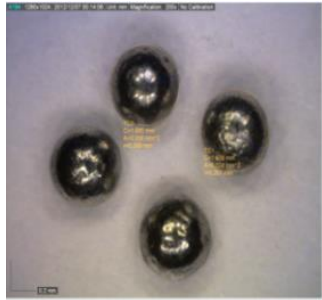

(c) $f=3 \mathrm{~Hz}, \mathrm{D}=536 \mu \mathrm{m}$

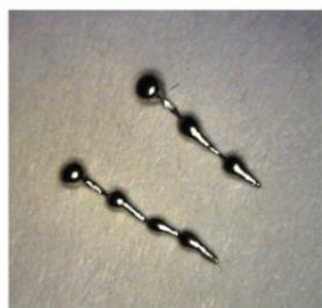

(e) $f=9 \mathrm{~Hz}$

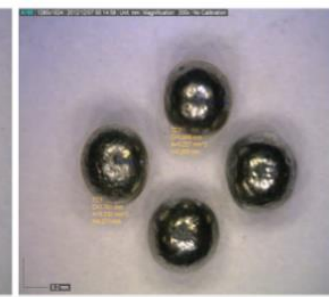

(b) $f=1 \mathrm{~Hz}, \mathrm{D}=542 \mu \mathrm{m}$

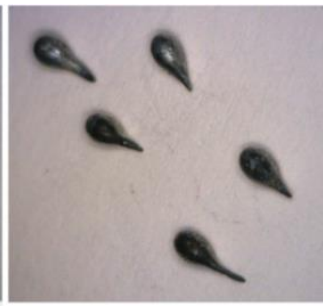

(d) $f=6 \mathrm{~Hz}$

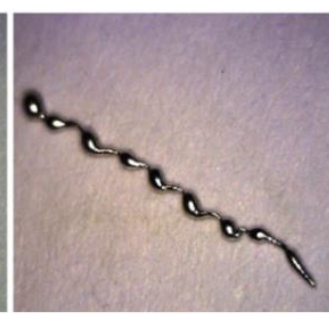

(f) $f=30 \mathrm{~Hz}$
Figure 4. Photographs ((a)-(f)) of products of molten metal ejected from orifice under different frequencies.
Figure 6. shows the photos of the high speed camera respectively.

The flight distance of the droplets was measured through image processing, and the velocity of droplets was measured $0.7 \mathrm{~m} / \mathrm{s}$.

\section{Accuracy of Positioning}

The distance of the nozzle and target point on the surface can reduce positioning accuracy. This may happen due to insufficient accuracy in machining of the rod or imperfect alignment of the rod and vibrator. Figure 7 shows the schematic of procedure for measuring the error and accuracy of the droplets positioning (Fig. 8). For this test, a straight line of droplets was dispositioned, where the value of $h_{n}$ of each droplet, (position of the head of the nozzle at the beginning) was different. When $h_{n}$ is $3 \mathrm{~mm}$, the initial position of the head end is $0.5 \mathrm{~mm}$, and the amplitude is $1.5 \mathrm{~mm}$, the value of error is less than $\pm 20 \mu \mathrm{m}$ which is an acceptable error for rapid prototyping according to the size of droplets.
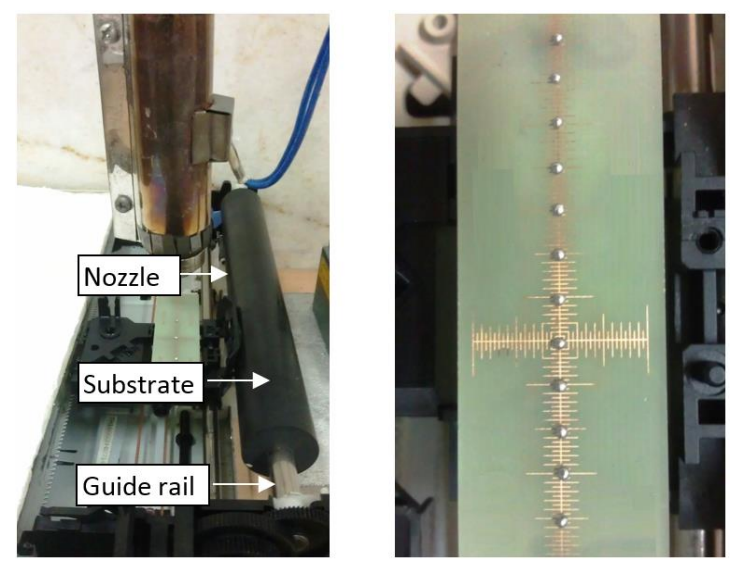

Figure 5. Experimental results of the drop-ondemand deposition of droplets.

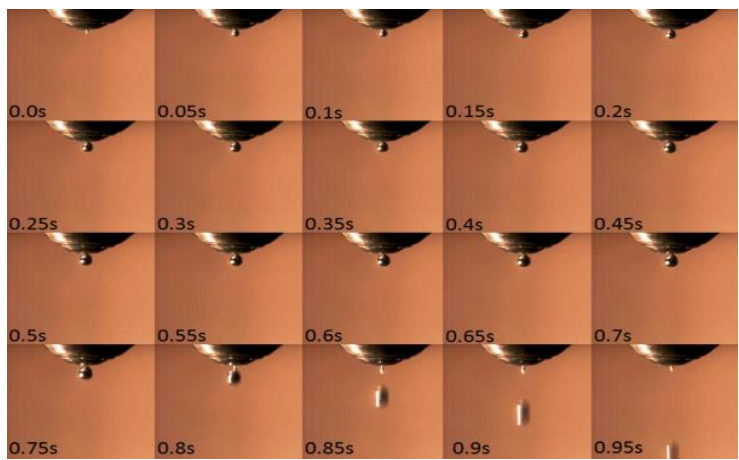

Figure 6. Photograph of metal droplet ejected from nozzle. 


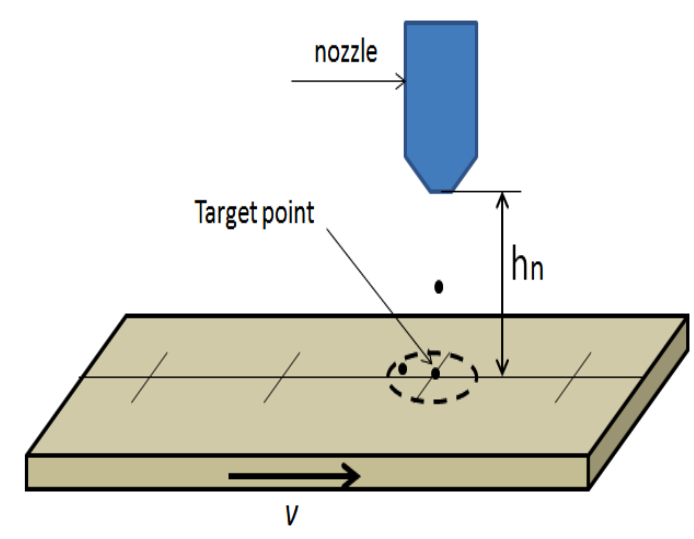

Figure 7. Schematic of tests for measuring error.
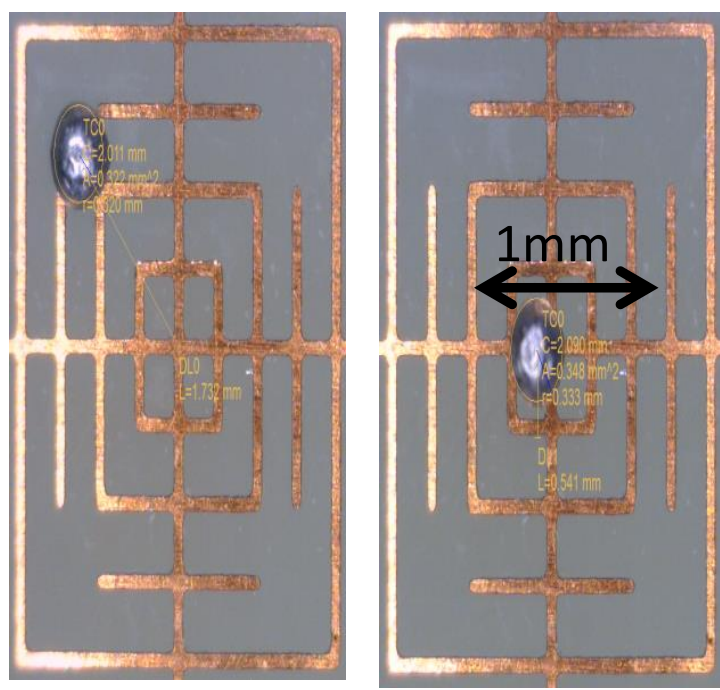

Figure 8. Deposition error measurement.

\section{Conflict of Interest}

The authors declare no conflicts of interest.

\section{Funding}

No funding was received for this research.

\section{Acknowledgment}

The authors express their thanks to the Advanced Metrology Lab, Tarbiat Modares University, Iran, for their appreciated technical supports.

\section{References}

Beer SZ (1972), Liquid metal - chemistry and physics. Marcel Dekke, 474-488, New York.
Chun JH, Passow CH (1993), Droplet based manufacturing. Journal of Annals of the CIRP 42: 235-238.

Fan KC, Chen JY, Wang CH, Pan WC (2008), Development of a drop-on-demand droplet generator for one-drop-fill technology. Sensors and Actuators A: Physical 147(2): 649-655.

Ghodsi M, Ueno T, Teshima H, Hirano $\mathrm{H}$, Higuchi T, Summers E (2007), Zero-power positioning actuator for cryogenic environments by combining magnetostrictive bimetal and HTS. Sensors and Actuators A 135: 787-791.

Ghodsi M, Ueno T, Teshima H, Hirano H, Higuchi T (2007), Numerical modeling of iron yoke levitation using the pinning effect of high temperature superconductor. IEEE Transactions on Magnetics 43(5): 2001-2008.

Ghodsi M, Ueno T, Higuchi T (2008), Novel magnetostrictive bimetal actuator using permendur. Advanced Materials Research 47-50: 262-265.

Ghodsi M, Ueno T, Modabberifar M (2010), Quality factor, static and dynamic responses of miniature galfenol actuator at wide range of temperature. International Journal of Physical Sciences 6(36): 8143-8150.

Ghodsi M (2015), Optimization of mover acceleration in DC tubular linear direct-drive machine using response surface method. International Review of Electrical Engineering 10(4): 492-500.

Ghodsi M, Hosseinzadeh N, Ozer A, Rajabzadeh H, Garjasi VN, Hojjat Y, Talebian Sl, Sheykholeslami M, Al-Yahmadi A (2017), Development of gasoline direct injector using giant magnetostrictive materials. IEEE Transactions on Industry Applications 53(1): 521529.

Goldin R (1999), Flip chip bumping with high speed metal jet technology. Proceedings of NEPCON West'99, Los Anglos.

Hayes DJ, Wallace DB, Boldman MT (1993), Method and apparatus for dispensing spherical shaped quantities of a liquid solder. US Patent: 5: 229016.

Karafi MR, Ghodsi M, Hojjat Y (2015), Development of magnetostrictive resonant torsional vibrator. IEEE Transactions on Magnetics 51(9): 1-8.

Lawrence L, James L, Jennifer R (2017), Examine a 3D-printed carbon fiber part created using a direct-ink writing process developed at LLNL. Lawrence Livermore National Laboratory, USA. 
Liu Q, Orme M (1999), High precision solder droplet printing technology and the state-ofthe-art. Journal of Materials Processing Technology 115: 271-283.

Luo J, Qi LH, Zhou JM, Hou XH, Li HJ (2012), Modeling and characterization of metal droplets generation by using a pneumatic drop-on-demand generator. Journal of Materials Processing Technology 212(3): 718-726.

Manko HH (1979), Solders and soldering: materials, design, production, and analysis for reliable bonding. McGraw-Hill, New York.

Mohammadzaheri M, Qallaf A (2017), Nanopositioning systems with piezoelectric actuators, current state and future perspective. Science of Advanced Materials 9(7): 1071-1080.

Murr LE, Johnson WL (2017), 3D metal droplet printing development and advanced materials additive manufacturing. Journal of Materials Research and Technology.

Özer A, Ghodsi M, Sekiguchi A, Saleem A, AlSabari N (2015), Design and experimental implementation of a beam-type twin dynamic vibration absorber for a cantilevered flexible structure carrying an unbalanced rotor: numerical and experimental observations. Shock and vibration, Article ID 154892.

Rayleigh L (1878), On the instability of jets. Proceedings of the London Mathematical Society 10: 4-13.
Rayleigh L (1879), On the capillary phenomena of jets. Proceedings of the London Mathematical Society 29: 71-97.

Savarat F (1833), Memoire sur la constitution des veines liquids lances par des orifices circulaires en mince. Annales de Chimie et de Physique 53: 337-386.

Sadeghian H, Hojjat Y, Ghodsi M, Sheykholeslami MR (2013), An approach to design and fabrication of a piezo-actuated microdroplet generator. The International Journal of Advanced Manufacturing Technology 70(5-8): 1091-1099.

Sohn H, Yang KY (2005), Drop-on-demand deposition of superheated metal droplets for selective infiltration manufacturing. Journal of Materials Science and Engineering 392: 415-421.

Waldvogel JM, Poulikakos D, Wallace DB, Marusak RM (1996), Transport phenomena in Pico liter size solder droplet dispensing on a composite substrate. ASME Journal of Heat Transfer 118: 148-156.

Yingxue Y, Shengdong G, and Chengsong C (2004), Rapid prototyping based on uniform droplet spraying. Journal of Materials Processing Technology 146: 389-395.

Yamaguchi K, Sakai K, Yamanaka T, and Hirayama T (2000), Generation of threedimensional micro structure using metal jet. Journal of Precision Engineering 24(1): 2-8.

Zaugg FG, Wagner P (2003), Drop-on-demand printing of protein biochips arrays. MRS BULLETIN 28(11): 837-842.

\section{Appendix A}

Exit velocity of a molten metal from a small nozzle is around $1 \mathrm{~m} / \mathrm{s}$. According to the dimensions of nozzle in figure A-1 for calculating the speed of the guidance rod, we will have

$$
\begin{aligned}
& \frac{u}{U}=\left(\frac{D}{d}\right)^{2} \\
& \frac{1}{U}=\left(\frac{0.006}{0.0002}\right)^{2} \Rightarrow U=0.9 \mathrm{~m} / \mathrm{s}
\end{aligned}
$$

Where $U$ is the speed of the piston. We can write the Bernoulli equation

$$
\left(\frac{p}{\rho g}+\frac{v^{2}}{2 g}+z\right)_{1}=\left(\frac{p}{\rho g}+\frac{v^{2}}{2 g}+z\right)_{2}
$$

Where $\mathrm{p}$ is the pressure, $\mathrm{v}$ is the velocity, $\rho$ is the density of liquid and $\mathrm{z}$ is the height of the fluid. The $\mathrm{z}$ is equal, therefore we can write

$$
\left(\frac{p}{\rho g}+\frac{v^{2}}{2 g}\right)_{1}=\left(\frac{p}{\rho g}+\frac{v^{2}}{2 g}\right)_{2}
$$


In addition, we can calculate the pressure differentiation as

$$
\begin{aligned}
& p_{1}=p_{0}+\rho \frac{u^{2}-U^{2}}{2} \\
& \Rightarrow p_{1}-p_{0} \cong \rho \frac{U^{2}}{2}
\end{aligned}
$$

The density of the liquid in this experiment in test temperature is $7830 \mathrm{~kg} \cdot \mathrm{m}^{-3}$. By substituting this value in last equation we will have

$$
\Rightarrow p_{1}-p_{0} \cong 3170
$$

Moreover, the force of the piston can be written as

$$
\begin{aligned}
& \sum F=0 \Rightarrow \sum F=m a=0 \\
& \begin{array}{l}
\Rightarrow F=\left(p_{1}-p_{0}\right) A \Rightarrow F=3170 * \pi *(0.003)^{2} \\
\quad \Rightarrow F=0.09 \mathrm{~N}
\end{array}
\end{aligned}
$$

To simplify the equations we made some certain assumptions. In the real experiment, the piston has friction, there is heat transfer in the system and the liquid velocity is not continuous. Hence, this value of force for the piston is less than the real value.

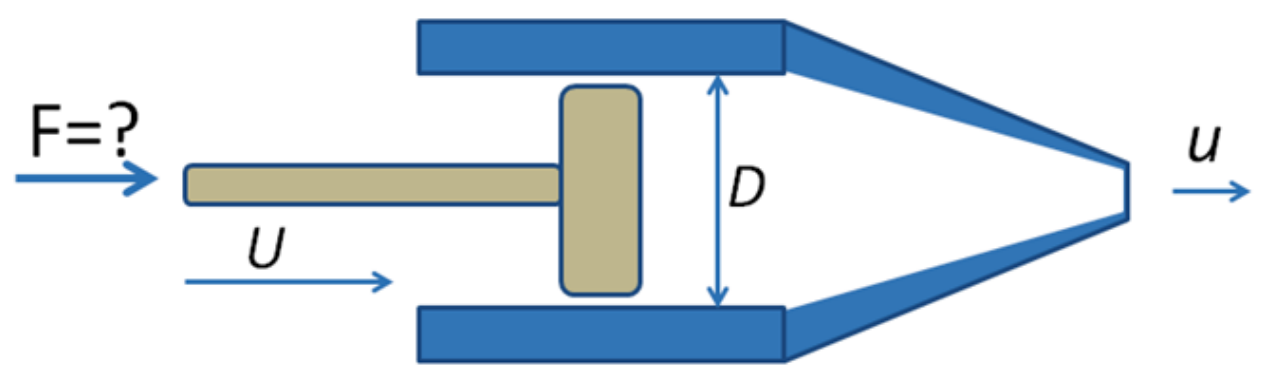

Figure A-1. Dimension and velocity direction of the nozzle.

For calculating the force of solenoid, thanks to Maxwell equation we can write

$F=B^{2} A /\left(2 \mu_{0}\right)$

Where $\mathrm{F}$ is the force of solenoid, $\mathrm{B}$ is the magnetic flux density and magnetic permeability of nozzle. Magnetic flux density can be written as

$B=\mu H \Rightarrow B=\mu_{0} \mu_{r}\left(\frac{N I}{L}\right)$

Where $\mathrm{N}$ is the number of turns in the coil, I is the current, $\mathrm{L}$ is the length of the coil, $\mu_{0}$ is permeability in vacuum and $\mu_{r}$ is the relative permeability. By substituting the values into equation we will have 


$$
\begin{aligned}
& B=4 \pi \times 10^{-7} \times 1000\left(\frac{200 \times 0.1}{0.042}\right)=0.598 T \\
& F=B^{2} A /\left(2 \mu_{0}\right)=9.05 N
\end{aligned}
$$

